\title{
Use of Contraceptive Methods in Couple's with Unplanned Pregnancies: A Population-Based Study among Iranian Population
}

\author{
Soodabeh Aghababaei ${ }^{1}$, Fatemeh Shobeiri ${ }^{1 \star}$, Raheleh Moien ${ }^{2}$ \\ ${ }^{1}$ Mother and Child Care Research Center, Hamadan University of Medical Sciences, Hamadan, Iran \\ ${ }^{2}$ Hamadan University of Medical Sciences \\ Accepted May 02, 2017
}

According to common complications of unplanned pregnancies and the necessity of the attention to different factors leading to these types of pregnancies. The purpose of this study was to evaluate the use of contraceptive methods in couple's with unplanned pregnancies referred to health centers in Hamadan city, Iran. In a cross-sectional study conducted on pregnant women who referred to health centers in Hamadan city for using prenatal caring from March 2006 to March 2007.Nine hundred women with unintended pregnancy were randomly selected for this study. The study data were collected by a validated questionnaire including questions about demographic characteristics, pregnancy and also family planning methods used before pregnancy. Data Processing and statistical analysis were performed using SPSS /16.0. Among 900 women with unplanned pregnancy, $\mathbf{9 2 . 2} \%$ experienced unplanned pregnancy for the first time and once and twice a history of unintended pregnancy was observed in $7.2 \%$ and $0.6 \%$ of cases, respectively. Among those, $93.9 \%$ used contraceptive methods. Hormonal methods were main used methods for contraception in $38.1 \%$, natural method was observed in $31.9 \%$ and periodic abstinence was the least used method $(0.4 \%)$. The main reasons for using irregular methods included inadequate information, lack of motivation and fear of side effects. Meaningful associations were found between the variables of age, age of spouse, educational level, number of parity, and history of abortion and the use of contraceptive methods. Multivariable logistic regression analysis showed that maternal age, educational level of woman and her spouse, and also number of parity were main indicators of the use of contraception. According to high rate of unplanned pregnancy in our population, planning more training and consulting sessions for improving couple's awareness about selection of the most appropriate family planning methods should be considered to reduce unintended pregnancy in our population.

Keywords: Unplanned pregnancy, Contraception Methods, Iran

\section{INTRODUCTION}

About 80 million women experienced unplanned pregnancy annually that among them, 42 million resort to abortion and 19 millions are unsafe that result in death in 67000 of cases (World Health Organization, 2008). Due to poor health outcomes associated with the mother and fetus, unintended pregnancy should be considered an important public health problem

*Corresponding Author Email:fshobeiri@yahoo.com
(Finer \& Henshaw, 2006). Unplanned pregnancy is a marker for unwillingness to pregnancy and is usually accompanied with medical, psychological, social, and even economic complications for women, family, and community (Xaverius, et al., 2009). Various studies indicated that unplanned pregnancy is more related to the problems including reduced prenatal care, misbehavior, increased complications within and after pregnancy, as well as low birth weight and infant mortality in comparison with planned pregnancy. Furthermore, long-term complications of unplanned pregnancy including 
increased risk of mental retardation, cerebral palsy, familial problems, violence against children and other psychosocial events are the most common adverse consequences of unintended pregnancy (Xaverius, et al., 2009; Mohllajee, et al.,2007). Risk of unplanned pregnancy in women who use contraceptive methods is much less. Strong evidence suggests that with better access and appropriate use of family planning methods, rate of abortion and its-related complications can be considerably reduced. Six Family planning is a set of proceedings to ensure human rights for planning to achieve a desired number of children and the spacing and timing of their births (Molina, et al., 2010).

There is no ideal method of contraception, the effective of the methods of contraception is dependant on one's impulse to use. Developing a convenient and reversible method with no side effects, and with complete effectiveness is impossible (Wildsmith, et al., 2015). Several factors can affect the choice of appropriate contraceptive methods especially in couples who are at risk of pregnancy included access to service provider, couple's believe in the effectiveness of existing methods, couple's fertility intentions, and their information level of existing methods and quality of the education system (Bensyl, et al., 2005). Many studies have shown that the lack of knowledge and access problems are two major reasons for not using contraceptive methods. 8 Previous studies on unwanted pregnancies and the use of contraceptive methods have produced other factors such as demographic and socioeconomic factors, health care parameters, counseling on family planning, sexual relationships and factors related to contraceptive method (Frost, et al. 2007; Wu, et al.2008; Kramer, et al., 2007, Ali Mohammadi, et al., 2014). Despite the widespread use of contraception in France, nearly a third of pregnancies are unintended and $65 \%$ of these cases occur in persons who have been used contraceptive methods at the time of pregnancy (Moreau, et al., 2007). In Iran, despite the availability of contraceptive methods, unplanned pregnancy is common. In a study by Abbasi, it was reported that $35 \%$ of 5427 pregnancies were unplanned (Abbasi Shavazi, 2004). According to common complications of unplanned pregnancies and the necessity of the attention to different factors leading to these types of pregnancies, this study carried out to evaluate the use of contraceptive methods in couple's with unplanned pregnancies referred to health centers in Hamadan city in from March 2006 to March 2007, Iran.

\section{METHODS}

This cross-sectional study was conducted to determine frequency of the use of contraceptive methods in women with unplanned pregnancy in Hamadan city, Iran, from March 2006 to March 2007.Total number of birth in Hamadan city was 12922 in the same study period.
Our target population included all women who referred to health centers in Hamadan for using prenatal caring that among them, 900 women with unplanned pregnancy were randomly selected for this study. The study data were collected by a validated questionnaire that its content validity was confirmed based on opinions of ten experts in the university (Abbasi Shavazi, 2004). The questionnaire included questions about demographic characteristics, pregnancy and also family planning methods used before pregnancy. After selection, the participants explained that the study did not have any effect on the quality of health services and questions and answers were completely confidential. The study was performed according to the Helsinki declaration protocol. The objectives of the study were explained to the women, and informed consent was obtained from all participants. Women could leave the study at any time. The study was approved by the Ethical Committee of Hamadan University of Medical Sciences. Results were reported as mean \pm standard deviation (SD) for the quantitative variables and percentages for the categorical variables. Predictors exhibiting a statistically significant relation with unplanned pregnancy were taken for multivariate logistic regression analysis to investigate their independence as predictors. $\mathrm{P}$ values less than 0.05 was considered statistically significant. Data Processing and statistical analysis were performed using SPSS /16.0.

\section{RESULTS}

The mean age of participants was $26.0 \pm 2.8$ years and most of them ranged 26 to 30 years. Most of them $(86.8 \%)$ were housewife and $63.6 \%$ had undergraduate educational degree. $92.0 \%$ had no history of abortion. $92.2 \%$ experienced unintended pregnancy for the first time and once and twice a history of unplanned pregnancy was observed in $7.2 \%$ and $0.6 \%$ of cases, respectively. most of the women used contraceptive methods (Table 1). Among 900 participants, 93.9\% used contraceptive methods. The main causes of failure to use family planning methods are presented in Table 2 . Hormonal methods were main used methods for contraception in $38.1 \%$, natural method was observed in $31.9 \%$ and periodic abstinence was the least used method $(0.4 \%)$. The main reasons for using irregular methods included inadequate information, lack of motivation and fear of side effects. Among study variables, educational level was significantly related to the use of contraceptive methods $(p<0.001)$ assessed by the chi-square test. Also, $t$ test analysis showed meaningful associations between the variables of age, age of spouse, number of parity, and history of abortion and the use of contraceptive methods $(p<0.001)$. multivariable logistic regression analysis showed that maternal age, educational level of woman and her spouse, 
Table 1: Frequency of the use of contraceptive methods in women with unplanned pregnancy

\begin{tabular}{lc}
\hline Contraceptive methods & Frequency (\%) \\
\hline Hormonal method & $322(38.1)$ \\
Natural method & $269(31.9)$ \\
Condom & $167(19.8)$ \\
Breastfeeding & $37(4.4)$ \\
IUD & $30(3.6)$ \\
Urgency & $16(1.9)$ \\
Periodic abstinence & $3(0.4)$ \\
\hline
\end{tabular}

Table 2: The main causes of failure to use family planning methods in women with unplanned pregnancy

\begin{tabular}{lcc}
\hline Contraceptive methods & The most common cause of failure & Frequency (\%) \\
\hline Hormonal method & Irregular and improper use & $181(59.9)$ \\
Condom & Improper use & $52(28.9)$ \\
Breastfeeding & Improper use and out of the first six months of pregnancy & $37(100)$ \\
IUD & No refer to control, lack of attension to necessary advice & $24(83.7)$ \\
Urgency & A mistake in taking a number of pills & $8(50.0)$ \\
Periodic abstinence & A mistake in calculating & $3(100)$ \\
\hline
\end{tabular}

Table 3: The main indicators of the use family planning methods in women with unplanned pregnancy

\begin{tabular}{lccc}
\hline Item & $\mathbf{- 2 L o g ~ R}$ & Freedom degree & P-value \\
\hline Maternal age & 7.252 & 1 & 0.001 \\
Mother educational level & 8.100 & 1 & 0.002 \\
Age of spouse & 2.478 & 1 & 0.271 \\
Spouse educational level & 6.983 & 1 & 0.002 \\
Parity & 9.364 & 1 & 0.005 \\
\hline
\end{tabular}

and also number of parity were main indicators of the use of contraception (Table 3).

\section{DISCUSSION}

Our study showed that the majority of participants used contraceptive methods. In a study by Xaverius et al, onethird of cases and in another study by foster, $9.0 \%$ of women used these methods (Xaverius, et al., 2009). In a study in the United States, half of unplanned pregnancies were observed in the group which used contraceptive methods (Finer \& Henshaw, 2006). In our observation, majority of women preferred to apply hormonal methods for contraception, followed by natural methods, condom, breastfeeding, urgency, and periodic abstinence. In Adebola et al. survey, the most common methods for contraception included condom and oral contraceptives (Adebodla, 2005). In a research by Ram, most of the participants used oral contraceptives, followed by condom, IUD, and natural methods (Ram, et al., 2014). In another study, the most important cause of unplanned pregnancies was failure to use family planning methods related to the use of condom, IUD, and periodic abstinence (Ross, et al., 2015). In current study, the most common causes of failure to use contraceptive approaches were irregular and improper use of oral contraceptive drugs that were mainly due to lack of awareness, lack of motivation, as well as fear of side effects. A study in the United Kingdom showed that the main cause of unplanned pregnancies was forgetting drug consumption or no protection at gastrointestinal diseases. That study also suggested that most unintended pregnancies occurred when contraceptive methods were used improperly or irregularly (Palanivelu \& Oswal, 2007). In the study, the occurrence of errors in the use of oral contraceptives could increase the refractive index from one in a thousand to $8 \%$ (Glasier, 2006 ). In another study, one of the causes of failure in the use of inject able contraceptive was irregular use so that about $50 \%$ of users stopped taking it after a year due to appearance of menstrual disorders (Halpern, et al., 
2015). In current survey, the failure rate in the use of IUD was the lowest and the most common cause of this failure was uncontrolling these devices (Saxena, et al., 2006). In the present study, improper and irregular use of condom remained the leading cause of failure in view of the subjects. In a study by Grims, the most significant factors in the failure of the condom use were fertility, and frequency and method of intercourse (Grimes \& Schlz, 2005). In the present research, the use of natural method with high failure rate led to unplanned pregnancy in $31.9 \%$ of the cases that was consistent with the study by Abbasi with $30.0 \%$ unintended pregnancy rate in women used natural method (Abbasi Shavazi, 2004).

In this study, there were significant associations of educational level, maternal age, age of spouse, number of parity, and abortion with the use of contraception. In a study by Ramezani and his colleagues, education level of women and their spouses as well as previous experiences of using these methods were introduced as the main determinants of the use of contraception (McKeating, et al., 2015). Another study indicated that main barriers for the use of contraception included inaccessibility, cost, social abnormalities, and fear of side effects. Also, indicated that age, race, marital status, tend to fertility, education level, and income were important factors in the choice of contraceptive methods (Elaut, et al., 2015).

In other observation, the rate of unplanned pregnancy was estimated $26.9 \%$ that among them $42.0 \%$ used advanced methods of contraception. In their study, 53.8\% of women used contraceptive methods improperly. Also, similar to our study, occurrence of unplanned pregnancy was significantly associated with age, educational level, education level of spouse, number of parity, gender of children, and knowledge towards availability of contraceptive devices (Nojoumi \& Zeinali, 2004). In Vakili et al. study, the incidence of unplanned pregnancy in urban and rural areas of Yazd city was $22.9 \%$ and $28.9 \%$, respectively. Maternal age, education status of mother and her spouse, number of children, satisfaction of income, history of unplanned pregnancy, and opinion of spouse about using contraceptives were main indicators of unplanned pregnancy (Vakili, et al., 2011). The study in 2010 showed that significant association of improper use of contraceptives with women occupation and their education level, duration of marriage, and number of children (Moravveji, et al., 2010). In a regression analysis, they were also demonstrated that occupation $(\mathrm{OR}=2.2)$, age $(\mathrm{OR}=1.7)$, duration of marriage $(\mathrm{OR}=$ $1.07)$, and age of the last child $(\mathrm{OR}=1.5)$ positively and number of children $(\mathrm{OR}=0.34)$ was inversely associated with improper use of contraceptives (Moravveji, et al., 2010).Totally, it seems that lack of knowledge and motivation and also improper use of contraceptive methods had major role in failure to use family planning methods that was similarly introduced by previous observations (Vakili, et al., 2011).Thus, for achieving successful contraception, the use of more effective and long-acting contraceptive methods besides improvement of couple's knowledge towards selecting the most appropriate methods should be planned ( Moravveji, et al., 2010; McKeating, et al., 2015; Kottke \& Cwiak, 2008; Kornides, et al., 2015).

In conclusion, despite availability of appropriate methods for contraception, our subjects prefer to use methods with the highest failure rate such as natural method or condom. Also, occurrence of unplanned pregnancy was also associated with improper and irregular use of contraceptive methods. Therefore, planning more training and consulting sessions for improving couple's awareness about selection of the most appropriate family planning methods should be considered to reduce unplanned pregnancy in our population.

\section{Acknowledgements}

The authors sincerely acknowledge the Hamadan University of Medical Sciences in Iran for their valuable support and participation. The study was approved by the Ethical Committee of Hamadan University of Medical Sciences.

\section{Funding/Support}

The project has been funded by Research Deputy of Hamadan University of Medical Sciences, Hamadan, Iran.

\section{Conflict of interest statement}

The authors declare that they have no conflicts of interest.

\section{References}

Abbasi Shavazi MJ (2004). Unintended pregnancies in the Islamic Republic of Iran: levels and correlates. Asian-Pacific Population Journal; 19(1): $27-38$.

Adebola OK (2005). Use of contraceptives and reproductive health knowledge aming adolescent mothers in Amukoko, A suburban community in Lagos, Nigeria.Abstracts Contraception; 72(3): 229245.

Ali Mohammadi SH, Sangin Abadi M, Saeif Rabiei MA, Shobeiri F (2014) A Comparative evaluation of maternal \& Neonatal complications in women between outpatients \& Inpatients with Preterm Premature Rupture of the membranes. Scientific Journal of Hamadan Nursing \& Midwifery Faculty; 22(2): 26-32.

Bensyl DM, Iuliano D, Carter M, Stantelli J (2005). Contraceptive use United States and behavioral risk factor surveillance system. Surveillance Summaries; 54(6): 1- 72.

Elaut E, Buysse A, Caen M, Vandamme J, Vermeire K, T'Sjoen G (2015). Contraceptive use in Flanders (Belgium): A comparison 
between a general population sample and a Turkish ethnic minority sample. Eur J Contracept Reprod Health Care; 25:1-13.

Finer LB, Henshaw SK (2006). Disparities in rates of unintended pregnancy in the United States. Perspect Sex Reprod Health; 38(2): 90-96.

Frost JL, Singh S, Finer LB (2007). Factors associated with contraceptive use and nonuse. Perspect Sex Reprod Health; 39(2): 90-99.

Glasier A (2006).Combined hormonal contraception. Medicine; 34(1): 1-5.

Grimes DA, Schulz KF (2005). Surrogate end points in clinical researchhazardous to your health. Obstet Gynecol; 105(5): 1114-1118.

Halpern V, Stalter RM, Owen DH, Dorflinger LJ, Lendvay A, Rademacher KH (2015). Towards the development of a longer-acting injectable contraceptive: past research and current trends. Contraception; S0010-7824.

Kornides ML, Kitsantas P, Lindley LL, Wu H (2015). Factors associated with young adults' pregnancy likelihood. J Midwifery Womens Health;60(2):158-168.

Kottke M, Cwiak C (2008). Nondaily contraceptive options user benefits, potential for high continuation, and counseling issues. Obstet Gynecol Surv; 63(10): 661-668.

Kramer MR, Hogue CJ, Gaydos LM (2007). Non contraceptive behavior in women at risk for unintended pregnancy: what's religion got to do with it?. Ann Epidemiol; 17(5): 327-334.

McKeating A, Maguire PJ, Farren M, Daly N, Sheehan SR, Turner MJ (2015). The clinical outcomes of unplanned pregnancy in severely obese women. J Matern Fetal Neonatal Med; 3:1-5.

Mohllajee AP, Curtis KM, Morrow B (2007). Pregnancy intention and its relationship to birth and maternal outcomes. Obstet Gynecol; 109(3): 678-686.

Molina RC, Roca CG, Zamorano JS, Araya EG (2010). Family planning and adolescent pregnancy. Best Pract Res Clin Obstet Gynaecol; 24(2): 209-22.

Moravveji AR, Atoof F, Madihi A, Safazadeh Z (2010). Modeling the determinants of unsafe contraception application in Kashan. city, Iran. Journal of Kashan University of Medical Sciences; 13(4): 294300.

Moreau C, Trussell J, Rodriguez G, Bajos N, Bouyer J (2007).Contraceptive failure rates in France: results from a population-based survey. Hum Reprod; 22(9):2422-7.

Nojoumi M, Zeinali Z (2004). Study of Unintended Pregnancy Prevalence and Related Factors in Women Referred to Prenatal Clinics of Akbar Abadi and Rasoul-e-Akram Hospitals in 2002 . Razi Journal of Medical Sciences; 12(45): 195-200 .

Palanivelu LM, Oswal A (2007). Contraceptive practices in women with repeat termination of pregnancies. J Obstet Gynaecol; 27(8): 832834.

Ram F, Shekhar C, Chowdhury B (2014).Use of traditional contraceptive methods in India \& its socio-demographic determinants. Indian J Med Res;140 Suppl:S17-28.
Ross J, Keesbury J, Hardee K (2015). Trends in the contraceptive method mix in low- and middle-income countries: analysis using a new "average deviation" measure. Glob Health Sci Pract; 3(1):34-55.

Saxena S, Copas AJ, Mercer C, Johnson AM, Fenton K, Erens B, Nanchahal K, Macdowall W, Wellings K (2006). Ethnic variations in sexual activity and contraceptive use: national cross-sectional survey. Contraception;74(3):224-233.

Vakili M, Shahbazi H, Dehghani MH (2011).The Prevalence of Unintended Pregnancies and its Related Demographic Factors in Hospitals of Yazd City. Journal of Toloo-e-behdasht, 9(4): 23-36.

Wildsmith E, Manlove J, Steward-Streng N (2015). Relationship characteristics and contraceptive use among dating and cohabiting young adult couples. Perspect Sex Reprod Health;47(1):27-36.

World Health Organization (2008). Improving sexual and reproductive health is at the core of achieving Millennium Development Goal 5. Available http://www.who.int/making_pregnancy_safer/events/2008.

Wu J, Meldrum S, Dozier A, Stanwood N, Fiscella K (2008).Contraceptive nonuse among US women at risk for unplanned pregnancy. Contraception; 78(4): 284-289.

Xaverius PK, Tenkku LE, Salas J (2009). Differences Between Women at Higher and Lower Risk for an Unintended Pregnancy. Women's Health; 19(5): 306- 312. 